\title{
The statistics of blowing snow occurrences from multi-year autonomous snow flux measurements in the French Alps
}

\author{
Zhipeng $\mathrm{Xie}^{1}$, Yaoming $\mathrm{Ma}^{1,4}$, Weiqiang $\mathrm{Ma}^{1,4}$, Zeyong $\mathrm{Hu}^{2}$, Genhou Sun ${ }^{3}$
}

${ }^{1}$ Land-Atmosphere Interaction and its Climatic Effects Group, State Key Laboratory of Tibetan Plateau Earth System, Resources and Environment (TPESRE), Institute of Tibetan Plateau Research, Chinese Academy of Sciences, Beijing 100101, China.

${ }^{2}$ Key Laboratory of Land Surface Process and Climate Change in Cold and Arid Regions, Northwest Institute of Eco10 Environment and Resources, Chinese Academy of Sciences, Lanzhou, 730000, China.

${ }^{3}$ School of Atmospheric Sciences, Sun Yat-sen University, 135 Xingang Xi Road, Guangzhou, 510275, China.

${ }^{4}$ University of Chinese Academy of Sciences, Beijing, 100049, China.

Correspondence to: Zhipeng Xie(zp_xie@itpcas.ac.cn)

15 Abstract. Wind-driven snow transport has important implications for the spatial-temporal heterogeneity of snow distribution and snowpack evolution in mountainous areas, such as the European Alps. The climatological and hydrological significance of blowig snow occurrences have been extensively investigated using satellite and numerical models. However, knowledge of the spatiotemporal variability of blowing snow is in its infancy because of inaccuracies in satellite-based blowing snow algorithms and the absence of quantitative assessments. Here, we present the spatiotemporal variability and magnitude of blowing snow events, and explore the potential links with ambient meteorological conditions using near surface blowing snow observations from the ISAW outdoor environmental monitoring network. Results show frequent occurrence of blowing snow, and contrasting seasonal variability in the French Alps. On average, monthly blowing snow days range from 5.0 to 14.3 days when using the snow flux threshold of $0.1 \mathrm{~g} \mathrm{~m}^{-2} \mathrm{~s}^{-1}$. The minimum and maximum frequencies of blowing snow days are observed in September and January, respectively, accounting for between $16.7 \%$ and $46.1 \%$ of the month. However, the frequency of monthly blowing snow days varies widely between stations, and this variability is more pronounced at lower threshold levels. Blowing snow events with relatively high magnitudes of snow mass flux $\left(1.0 \mathrm{~g} \mathrm{~m}^{-2} \mathrm{~s}^{-1}\right)$ occur more frequently than low-intensity events (snow mass flux ranges from 0.1 to $0.5 \mathrm{~g} \mathrm{~m}^{-2} \mathrm{~s}^{-1}$ ). By imposing a minimum duration of $4 \mathrm{~h}$, the monthly cumulative hours with blowing snow occurrences can be up to 255 hours, but show significant seasonal and spatial variability. The considerable variability observed across this region can be explained by contrasting local climate (particularly

30 wind speed and air temperature), snowpack properties, topography and vegetation. The snow-mass transported during relatively high magnitude blowing snow events accounts for about $90 \%$ of all the transported snow mass, highlighting the importance of major events. Blowing snow events that occur with concurrent snowfall are generally associated with intense 
https://doi.org/10.5194/tc-2021-260

Preprint. Discussion started: 25 August 2021

(c) Author(s) 2021. CC BY 4.0 License.

(c) (i)

snow transport. Transport of wet snow and dry snow is mostly concentrated in the range of 0.1 to $0.5 \mathrm{~g} \mathrm{~m}^{-2} \mathrm{~s}^{-1}$ and 0.5 to $1.0 \mathrm{~g}$ $\mathrm{m}^{-2} \mathrm{~s}^{-1}$, respectively. Understanding the spatiotemporal variability of blowing snow occurrences and the potential links with

35 ambient meteorological conditions is critical for constructing effective avalanche disaster warning systems, and for promoting quantitative evaluation and development of satellite retrieval algorithms and blowing snow models.

\section{Introduction}

With high albedo and thermal emissivity, and low thermal conductivity, the presence of snow cover has a significant influence on the near-surface ground thermal regime in cold regions (Goodrich, 1982; Zhang, 2005) and palys an important role in the Earth's climate system through its impact on the surface energy budget (Cline, 1997; Chen et al., 2017) and the water cycle (Barnettt et al., 2005). The effects of snow cover on the ground thermal regime can be explained by interactions with micrometeorological conditions and ground features, such as vegetation and local topography. However, the overall impact fluctuates widely with the timing and duration of accumulation and melting of the snow cover (Zhang, 2005), both in magnitude and in its cooling or warming effect. Therefore, the spatial heterogeneity of snow cover exerts considerable

45 influence on the timing and magnitude of snow cover depletion and snowmelt runoff, which in turn controls energy fluxes between the land and the atmosphere (Berghuijs et al., 2014; Musselman et al., 2021). Changes in snow distribution exert strong and far-reaching climatological and hydrological effects on the global climate systems (Dery and Yau, 2002; Zhang, 2005; Xiao, 2021).

The spatial distribution of snow cover is highly heterogeneous over complex terrain and vegetation in mountainous areas,

50 and snow redistribution by wind plays an important role. Deposited snow particles are eroded and transported downwind via snow creep, saltation and suspension processes, leading to considerable snow-mass movement from wind-exposed surfaces (e.g., flat surfaces, hilltops, windward slopes, and sparsely vegetated surfaces) to wind-sheltered areas such as leeward slopes, more densely vegetated regions and topographic depressions ( $\mathrm{Li}$ and Pomeriy, 1997; Liston and Sturm, 1998). The action of blowing snow presents a substantial risk to human activities, threatening public safety and transportation because of reduced

55 visibility during severe blowing snow events (Huang et al., 2008; Letcher et al., 2021). Furthermore, snow accumulation resulting from the deposition of wind-blown snow can be many times greater than expected by natural snowfall alone (Mann et al., 2000), and is regarded as one of the most important factors for avalanche forecasting (Guyomarc'h and Merindol, 1998; Vionnet et al., 2018). Locally increased snowdrifts and snow cornices in mountainous regions caused by blowing snow influence snowpack stability and have the potential for avalanche release (Naaim-Bouvet et al., 2014). Therefore, an accurate

60 forecast of the occurrence of blowing snow may help to minimize the risk and damage caused by aclanche (Vionnet et al., 2018).

Since snow cover patterns are extremely important for estimating hydrological and heat fluxes, improving the understanding of blowing snow occurrence is important to develop realistic physical models and quantify the contribution of blowing snow to the surface heat and moisture budgets. Numerous studies have attempted to accurately simulate the occurrence 
of blowing snow (Liston and Sturm, 1998; Pomeroy et al., 1993; Lenaerts et al., 2012; He and Ohara, 2017; Dery and Yau, 1999; Xie et al., 2019). Parameterization schemes generally fall into two categories: 1) empirical relationships describing blowing snow occurrence in terms of meteorology, terrain characteristics, and microstructural properties of the snowpack, such as snow density, the mean radius of snow particles and the bond diameter between particles (e.g., Schmidt, 1980, 1981; He and Ohara, 2017), and 2) physical-based models which include detailed algorithms calculating saltation, suspension and sublimation rates of blowing snow (e.g., Pomeroy et al., 1993; Dery and Yau, 1999). Although substantial progress has been made in the last few decades, contrasting results can be found in large-scale estimations of wind-driven snow processes. For example, the regional climate model MAR produces snow mass fluxes that are more than three times larger than the RACMO2 model, despite they share a similar overall spatial pattern (van Wessem et al., 2018; Agosta et al., 2019). Hence, Amory (2020) suggested the need for model intercomparisons and careful assessment of the assumptions made in the implementation of physical algorithms using independent observations from additional regions to where the empirical equations were developed.

Satellite remote sensing has recently been used to investigate blowing snow occurrences (Palm et al., 2011, 2018). While these techniques enable large scale data retrieval of blowing snow occurrence, the presence of clouds and the coarse vertical resolution lead to considerable uncertainty and hinder widespread applications in areas outside of Antarctica (Palm et al., 2011; Gossart et al., 2017). Moreover, ground validation remains essential to evaluate the remote sensing retrieved blowing snow occurrence. Various specific instruments ranging from mechanical traps or nets (e.g., Mellor, 1960) to optical (e.g., the Snow Particle Counter, SPC; Sato et al., 1993), and acoustic sensors (e.g., FlowCapt, Chritin et al. 1999) have facilitated direct observation of local blowing snow occurrence, and several measurement campaigns have been organized to investigate the spatialtemporal patterns (Leonard et al., 2012; Barral et al., 2014; Trouvilliez et. al., 2014). These observational data are essential for the development and evaluation of blowing snow parameterization and satellite retrieval algorithms. However,

85 direct blowing snow observations are limited to a few sites and are usually sparse in time and space due to the challenge of establishing a long-term observation platform in remote mountain areas with harsh climatic conditions.

Despite the sparsity and unevenly distribution of direct in-situ blowing snow observations, near-surface measurements of blowing snow have provided valuable and accurate information that cannot be sensed remotely or determined visually. These measurements are useful in assessing the ability of models and satellite retrieval algorithms to accurately capture the

90 spatiotemporal variability of blowing snow occurrences from a quantitative perspective. Understanding the occurrence of blowing snow under various meteorological conditions can facilitate the prediction of blowing snow initiation and snow transport, with broad implications for spatial snow distributions, snowpack dynamics and surface energy budgets.

This study aims to present the spatiotemporal variations in blowing snow occurrence in the French Alps and explore the potential links with ambient meteorological conditions using long-term meteorological data and FlowCapt measured snow 95 mass flux. While more work is needed to validate satellite-based retrievals or model simulations of blowing snow occurrence with point-scale measurements, we believe the work presented here lays a solid foundation for understanding regional characteristics of blowing snow occurrence by linking local measurements, satellite-based retrievals and model simulations. 


\section{Data and methodology}

\subsection{Sites and instrumentation}

This study was conducted in the Alps region, which is the highest and most extensive mountain range in Europe. Nine stations in Frence (Figure 1) were selected from about 30 ISAW stations where data has been released by IAV Engineering Ltd (www.iav.ch). The following criteria were designed for site selection to accurately characterize the occurrence of blowing snow events in this region:

- Long-term data availability - Only stations with at least ten years of observations were selected to reduce uncertainty and ensure reliability and consistency.

- Availability of meteorological measurements - Stations with wind speed (mean and maximum wind speed, wind direction), air temperature, precipitation, snow depth and FlowCapt blowing snow flux observations were selected to investigate the effect of meteorological conditions on blowing snow occurrence.

- Daily observation availability - Determining whether a blowing snow event occurs in a day requires near-complete records of hourly observations. Therefore, if more than half of the observations within a day were missing or of poor quality, these data were discarded.

- Monthly observation availability - The number of days in a month with blowing snow occurrence should represent the blowing snow conditions within that month but is heavily influenced by the proportion of days with available data. The number of days with occurrences of blowing snow was counted only when the days with available data exceeded the threshold values ( 23 days for February and 25 days for other months).

The blowing snow flux and surface meteorological data from the stations were compoled at hourly resolution. Observed surface meteorological variables include the mean and maximum wind speed, wind direction, air temperature, relative humidity, snow depth, and precipitation, although the data availability varies between stations. FlowCapt acoustic sensors (Chritin et al., 1999) are equipped at each ISAW station to measure blowing snow flux. This instrument consists of two $1 \mathrm{~m}$ long tubes containing electroacoustic transducers that omnidirectionally record the acoustic vibration generated by the collision of windborne snow particles with the tubes (Amory, 2020). These sensors can effectively and accurately discriminate the lowfrequency noise generated by the wind from the high-frequency blowing snow signal using electrical filtering and spectral analysis (Chritin et al., 1999; Amory, 2020). The FlowCapt can operate across a large climatic range and allows for continuous and automatic monitoring of snow-drifting as long as the sensor remains partially exposed. 
a)

(m)

b)

(m)

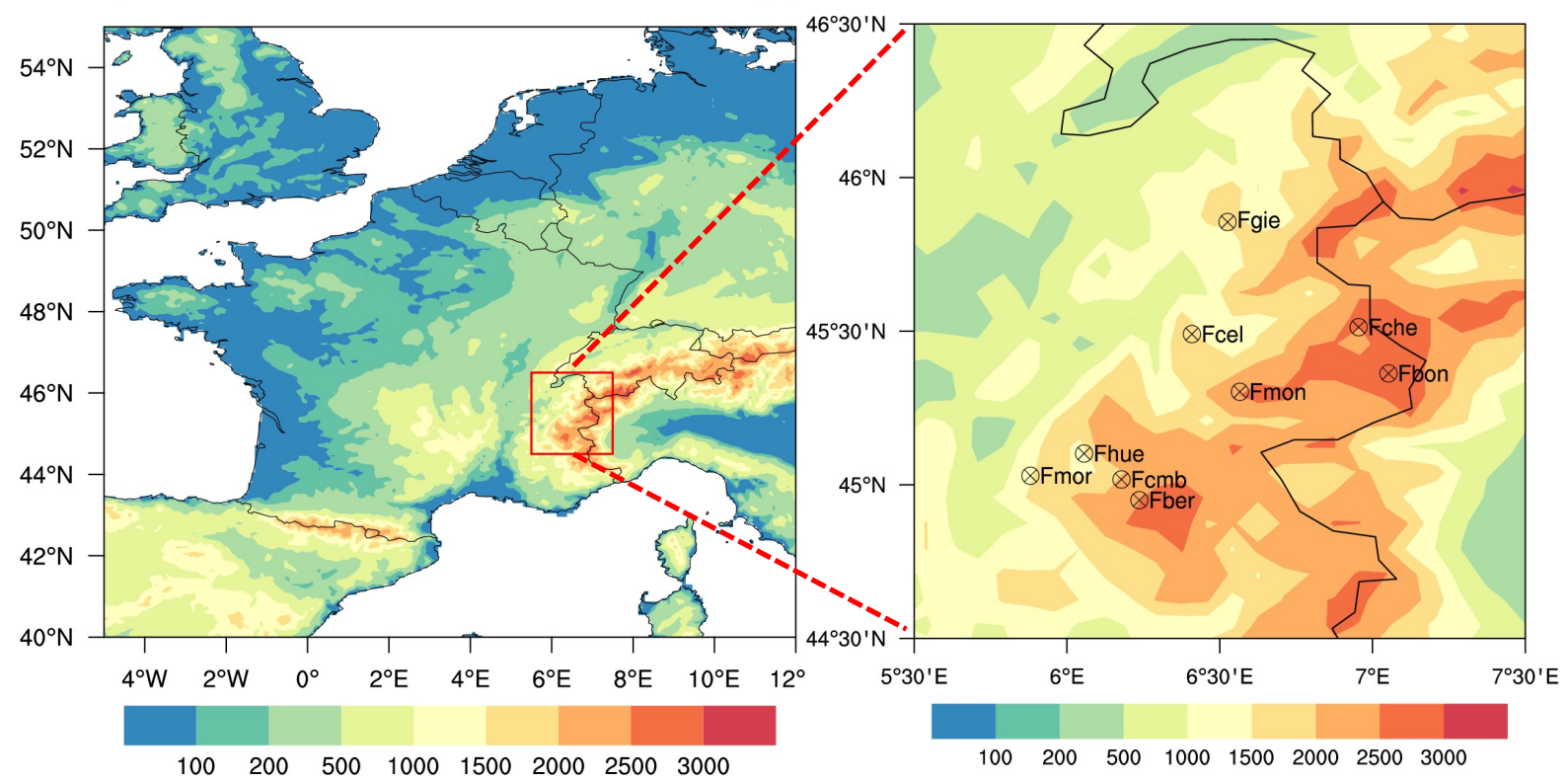

Figure 1. Location and elevations of the nine stations in this study.

The occurrence of blowing snow events is directly influenced by the ambient atmospheric conditions and internal physical properties of snowpack, such as different types of snow (Liston et al., 2007; Huang et al., 2018; Xie et al., 2019; Xie et al., 2021), meaning that investigating the potential impact of different meteorological factors under various conditions is necessary.

130 Nine stations (Figure 1) with wind speed (mean and maximum), wind direction, air temperature, snow depth and precipitation observations were selected to investigate the spatial and temporal variability of blowing snow occurrences in the French Alps.

\subsection{Data quality control}

Strict data selection criteria were applied to the in-situ observations following the procedures developed by Xie et al. (2021). A threshold check was performed for the mean and maximum wind speed and theair temperature; in addition, the

135 ranges of the mean and maximum wind speed and wind direction were also checked. For example, data were discarded for periods when the mean and maximum wind speed was zero for more than three consecutive hours or when wind direction and wind speed remained unchanged for more than three and five hours, respectively. Previous studies indicated that the FlowCapt sensor suffers from substantial uncertainty as a result of soil particles (Vionnet et al., 2018; Xie et al., 2021), as it is challenging to distinguish blowing snow occurrences from false signals caused by the impact of soil particles. Although the SR50 ultrasonic

140 sensor can provide surface snow cover information, its accuracy can be questionable, as discussed in Xie et al. (2021). Hence, records during the summer season (June, July and August) were discarded, and only observations during periods with snow cover were used to minimize the uncertainty of FlowCapt measurements. The blowing snow flux measured by the FlowCapt sensors were further analyzed to remove additional outlier measurements. For example, periods when sensors recorded 
https://doi.org/10.5194/tc-2021-260

Preprint. Discussion started: 25 August 2021

(c) Author(s) 2021. CC BY 4.0 License.

(c) (i)

blowing snow events in the absence of snow cover (determined according to the procedure used by Xie et al. (2021)), without concurrent snowfall or when positive air temperature lasted for more than 24 hours were discarded. The remaining records were used to reveal the spatial and temporal variability of blowing snow occurrence. Snow mass flux measurements can suffer from uncertainty caused by changes in the exposed length of the FlowCapt tube due to snow accumulation and ablation. However, no adjustment was made because of the inaccurate snow depth observations, and only relative values of snow mass flux were analyzed.

\subsection{Data classification}

To investigate the relationship between blowing snow occurrence and different meteorological conditions, the qualitycontrolled data were categorized into three types: snowfall (SF), surface covered by wet snow without concurrent snowfall (NoSF_WET), and surface covered by dry snow without concurrent snowfall (NoSF_DRY). Wet snow refers to snow that has either melted or received liquid precipitation since the last snowfall, while dry snow is defined as snow that has not been exposed to liquid precipitation or temperatures greater than $0{ }^{\circ} \mathrm{C}$ ( $\mathrm{Li}$ and Pomeroy, 1997).

In this study, the direct blowing snow flux measured by the FlowCapt sensors was used to identify blowing snow occurrence. Periods were identified as blowing snow events if at least two consecutive hours with blowing snow fluxes exceeding a confidence threshold (0.1, 0.5 and $1.0 \mathrm{~g} \mathrm{~m}^{-2} \mathrm{~s}^{-1}$ corresponding to relaxed, normal and strict criteria, respectively) were observed. The range of thresholds was used as a measure of uncertainty. The thresholds used in this study were different from values used by Amory (2020) from East Antarctica because the mass flux in the European Alps is significantly lower than in Antarctica. A day was classified as a blowing snow day if at least one blowing snow event was detected.

\section{Analysis of observations}

\subsection{Frequency of blowing snow occurrence}

The total number of blowing snow days (BSD) was extracted based on the different snow-mass thresholds to show the overall characteristics of seasonal variability in blowing snow occurrences. The monthly number of days with blowing snow (Figure 2) indicates that blowing snow occurrences are highly frequent in the French Alps. Generally, the frequency of blowing snow occurrence began to increase after September until a peak is reached during winter (December, January and February), and a gradual decrease is observed during spring. December and January were the two months with the most blowing snow days. Except for the Fcel station, where a minimum incidence of blowing snow was observed in October under the relaxed 0.1 $\mathrm{g} \mathrm{m}^{-2} \mathrm{~s}^{-1}$ threshold, other locations experienced the lowest frequency of blowing snow occurrence in September. The Fmor station experienced the highest incidence of blowing snow in September compared to other stations, with blowing snow events occurring 7.2, 5.6 and 4.5 days under the different thresholds, corresponding to $24 \%, 19 \%$ and $15 \%$ of the month, respectively. 
The BSD varies significantly during the year, particularly at the Fmor and Fcmb stations. When averaged across all stations (Figure 2j), the BSD values range from 5.0 to 14.3 days at the threshold of $0.1 \mathrm{~g} \mathrm{~m}^{-2} \mathrm{~s}^{-1}$, while for Fmor and Fcmb station, they 175 were 7.17 to 20.3 days and 3.0 to 19.5 days, respectively. Contrary to the pronounced seasonal difference observed at Fmor and Fcmb stations, the blowing snow frequency at Fmon station maintained at the relatively low but stable level through the year, with 5.7 days difference between the BSD in December (9.2 days) and September (3.5 days). In addition, the maximum BSD of the Fmon station was significantly lower than the average BSD of all stations (14.3 days) in January. Blowing snow event at the Fmor and Fcmb stations in January occurred as frequently as two out of every three days.
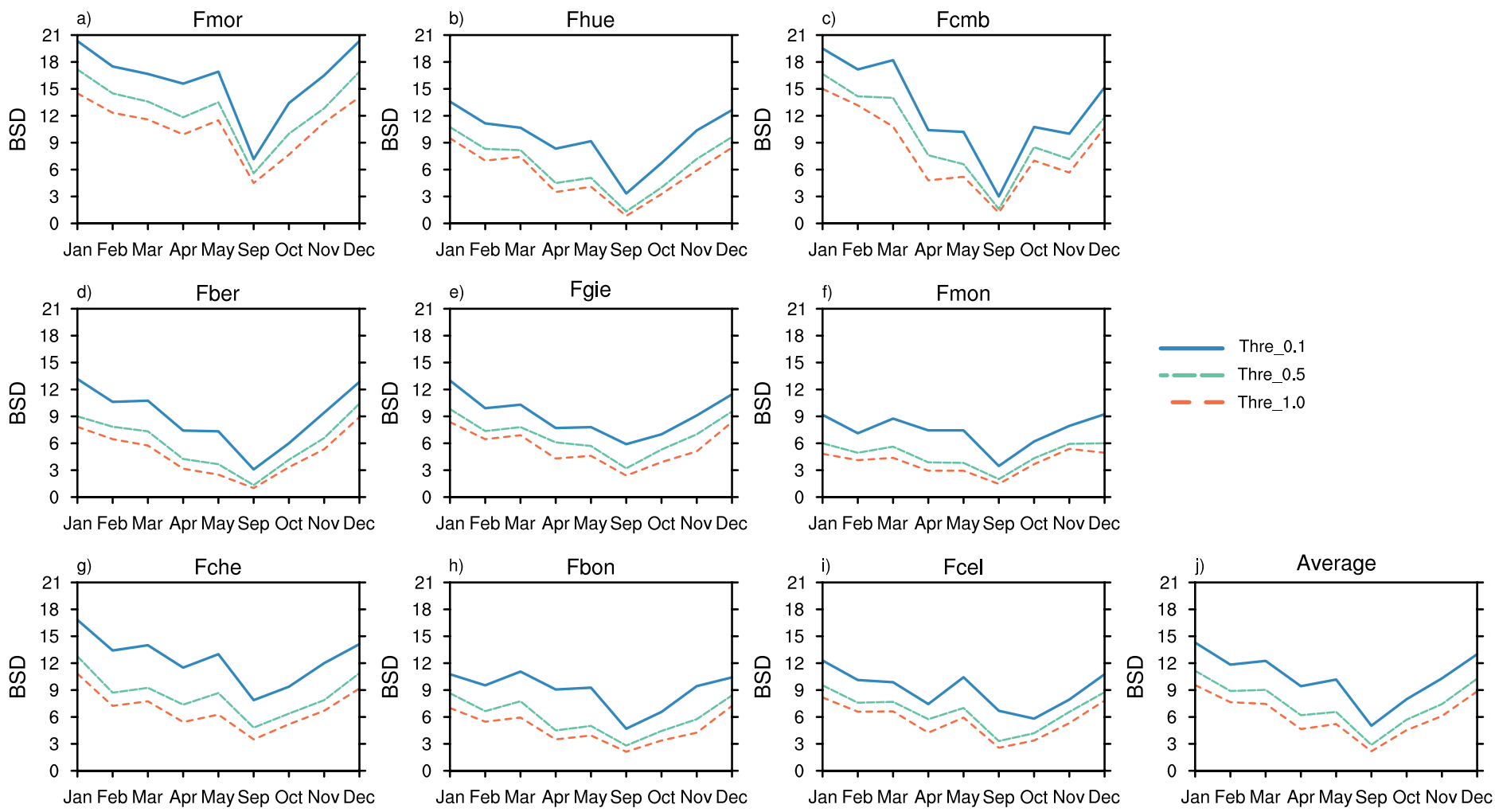

Figure 2. Seasonal variability in the monthly number of days with blowing snow occurrence (BSD) at each station.

Observations during the summer season are excluded to minimize the uncertainty from soil particles causing false signals.

BSD under a relaxed, moderate and stricter confidence threshold of 0.1 (solid blue line), 0.5 (dashed green line) and $1.0 \mathrm{~g} \mathrm{~m}^{-}$ ${ }^{2} \mathrm{~s}^{-1}$ (dashed red line) are shown as a measure of uncertainty. 

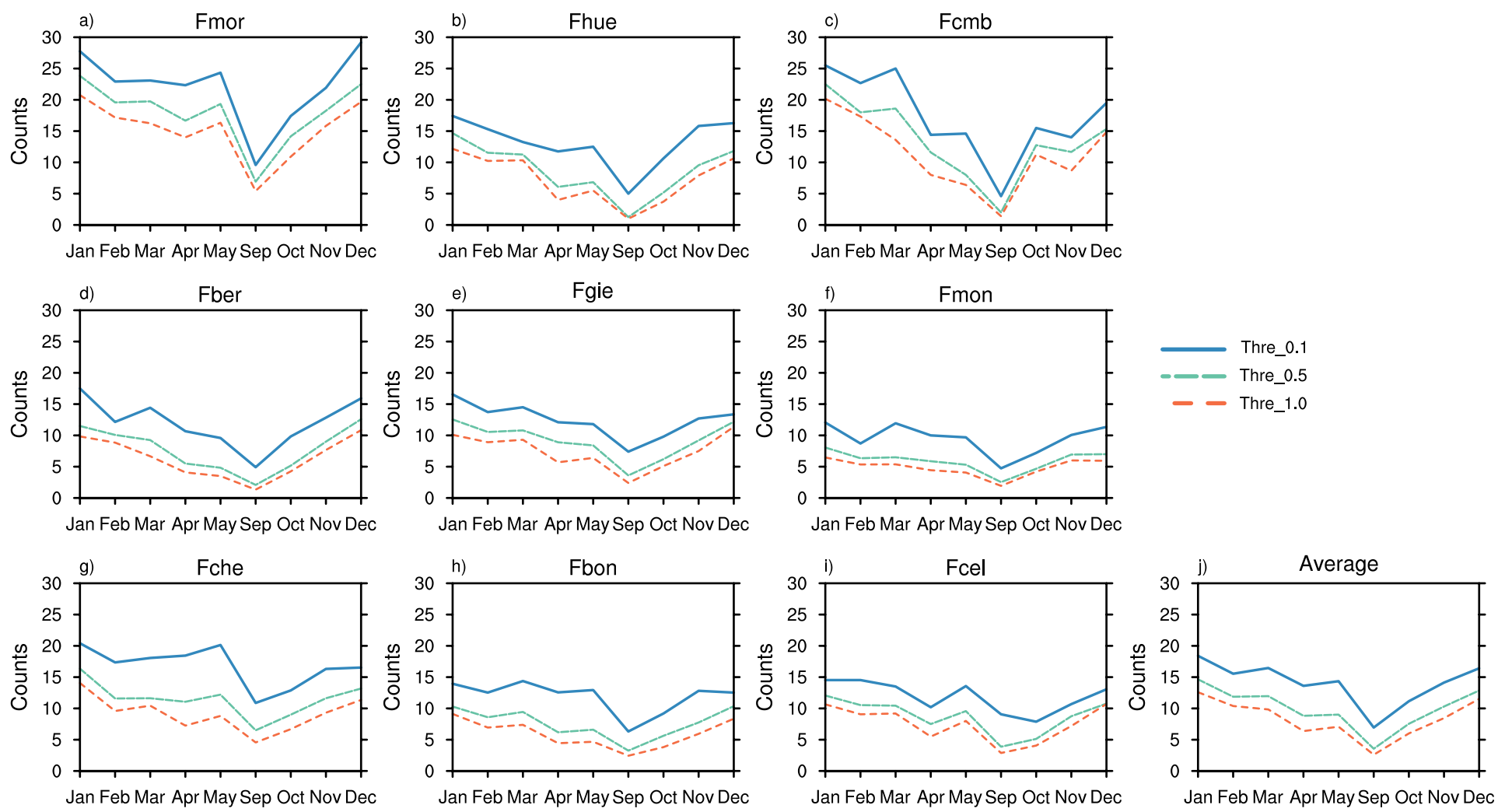

Figure 3. Seasonal variations in the number of blowing snow events at each station.

Comparison of the seasonal variability of BSD defined using different thresholds can reflect the uncertainty of FlowCapt measurements. The BSD at various thresholds showed very similar seasonal variability. The BSD at the stricter threshold of $1.0 \mathrm{~g} \mathrm{~m}^{-2} \mathrm{~s}^{-1}$ accounted for up to $77 \%$ (Fcmb station in January) of the total BSD, and the annual average value from different sites ranged from $51.3 \%$ (Fmon) to $66.7 \%$ (Fmor), suggesting that the occurrence of blowing snow in most stations was associated with relatively high magnitude snow mass flux. The difference of BSD at the threshold of $0.5 \mathrm{~g} \mathrm{~m}^{-2} \mathrm{~s}^{-1}$ and $0.1 \mathrm{~g} \mathrm{~m}^{-}$ ${ }^{2} \mathrm{~s}^{-1}$ was slightly higher than that between $1.0 \mathrm{~g} \mathrm{~m}^{-2} \mathrm{~s}^{-1}$ and $0.5 \mathrm{~g} \mathrm{~m}^{-2} \mathrm{~s}^{-1}$. The higher the difference of BSD between the two thresholds, the higher the frequency of blowing snow occurrence with a magnitude within these two thresholds. Taking the Fche station as an example, the BSD at the of $0.1 \mathrm{~g} \mathrm{~m}^{-2} \mathrm{~s}^{-1}$ threshold was roughtly 4 days higher than that at $0.5 \mathrm{~g} \mathrm{~m}^{-2} \mathrm{~s}^{-1}$, indicating that small magnitude (snow mass flux ranges from $0.1 \mathrm{~g} \mathrm{~m}^{-2} \mathrm{~s}^{-1}$ and $0.5 \mathrm{~g} \mathrm{~m}^{-2} \mathrm{~s}^{-1}$ ) blowing snow event occurred about

1954 days in each month. The different thresholds did not significantly affect the derived BSD patterns, and the stronger sensitivity to the lower threshold demonstrates the high frequency of high magnitude blowing snow events (Figure 2). The high frequency of high magnitude blowing snow events observed in this study is in agreement with the results of Guyomarc'h et al. (2019). These findings highlight the necessity to specify a moderate but appropriate threshold value to derive the incidence of blowing snow events from direct blowing snow mass flux sensors. 
https://doi.org/10.5194/tc-2021-260

Preprint. Discussion started: 25 August 2021

(c) Author(s) 2021. CC BY 4.0 License.

(c) (i)

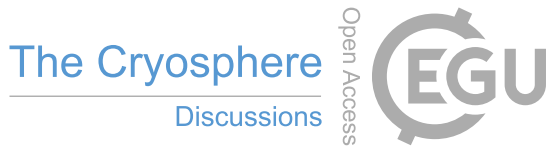

Figure 3 demonstrates the difference in BSD frequency between stations. Although these stations shared similar seasonal variations (Figure 2), the monthly BSD frequency varied widely between stations, and the differences were more pronounced at the lower mass-flux threshold. The greatest difference in monthly BSD frequency was $0.37,0.36$ and 0.32 for the three increasing thresholds, with the maximum difference of BSD from 9.92 to 11.47 days. The Fmor, Fcmb and Fche stations had the highest frequency of blowing snow occurrence, while the values at the Fmon, Fcel, Fgie and Fbon stations were below average in majority of months. In most cases, the Fmor station experienced much higher BSD than other stations. This phenomenon was more pronounced when compared with the BSD at the Fmon station. This significant spatial variability between stations did not depend on elevation and was likely related to local ambient conditions, such as wind speed and air temperature.

The pronounced seasonal differences in the number of blowing snow events shown in Figure 4 is highly consistent with 210 the respective seasonal variability in BSD. Similarly, significant variability in the number of blowing snow events was observed at the Fmor and Fcmb station, where the maximum number of blowing snow events can be up to 29.2 and 25.5, and the minimum numbers were 9.6 and 4.6, respectively. The blowing snow occurrences at Fmon, Fbon and Fcel stations were relatively stable, with only slight variation (about 7.0 days) throughout the year.
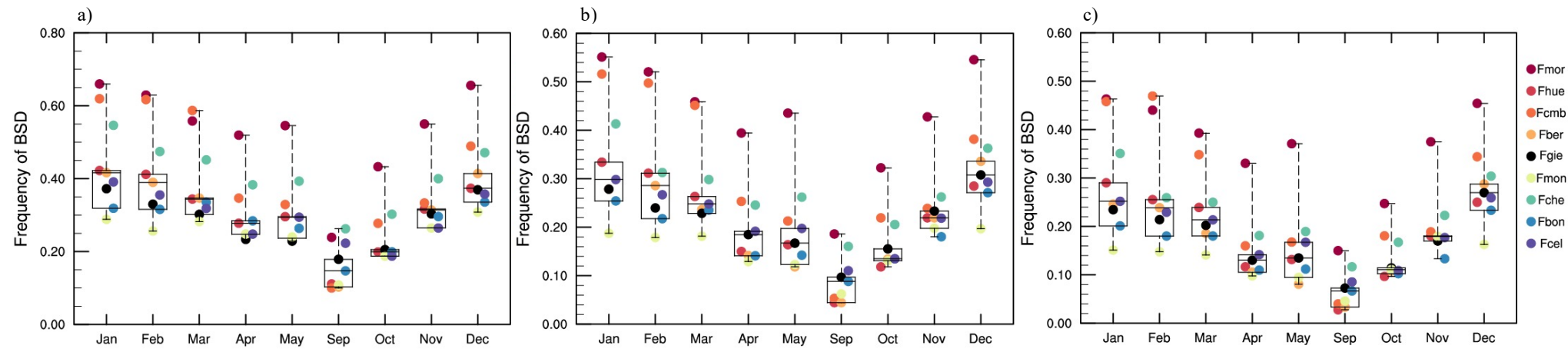

Figure 4. Spatial and temporal variability of monthly BSD frequency under the thresholds of 0.1 (a), 0.5 (b) and $1.0 \mathrm{~g}$ $\mathrm{m}^{-2} \mathrm{~s}^{-1}(\mathrm{c})$. Monthly BSD frequency from different stations are represented with different colors. 
https://doi.org/10.5194/tc-2021-260

Preprint. Discussion started: 25 August 2021

(c) Author(s) 2021. CC BY 4.0 License.

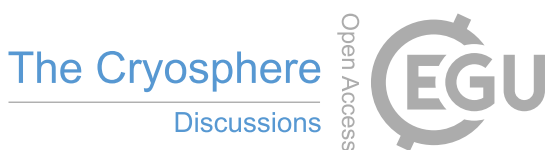

\subsection{Duration of blowing snow events}

The monthly values of BSD and the number of blowing snow events analyzed above show the spatiotemporal variability of blowing snow occurrence, and the following analysis illustrates the frequency of blowing snow occurrences in terms of duration.
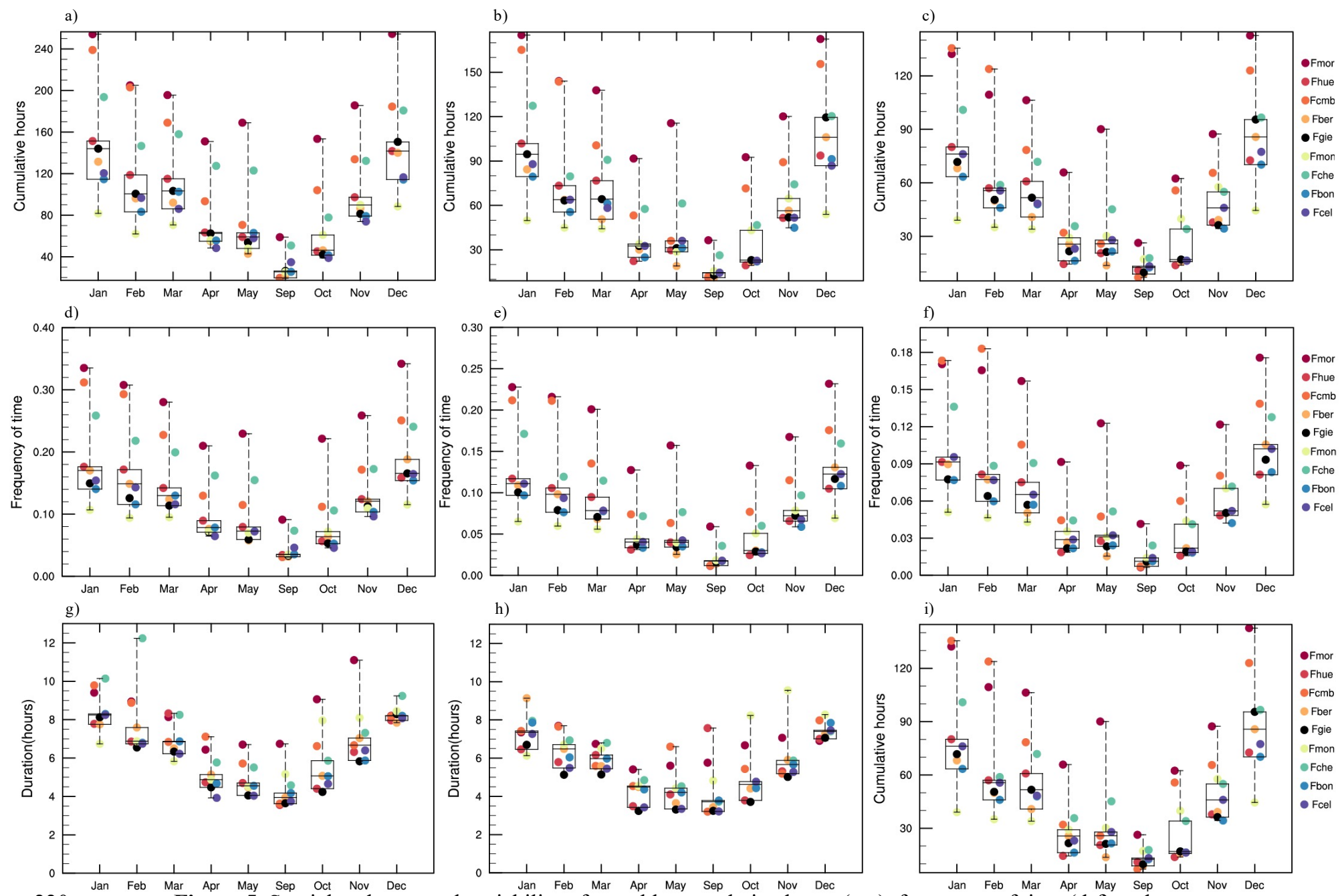

Figure 5. Spatial and temporal variability of monthly cumulative hours (a-c), frequency of time (d-f) and average

duration of each blowing snow event under the threshold of $0.1,0.5$ and $1.0 \mathrm{~g} \mathrm{~m}^{-2} \mathrm{~s}^{-1}$.

Blowing snow initiates once the wind shear stress provides enough driving force to overcome the snow cohesion, bonding and frictional resistance and stops when the wind diminishes and/or all loose snow on the ground has been transported and/or only compacted snow is left. Figure 5a-c presents the monthly accumulative hours where blowing snow was detected, the

225 frequency of blowing snow occurrence and the mean duration of each blowing snow event obtained under different confidence thresholds. The monthly occurrence of blowing snow events was obtained by dividing the monthly cumulative hours of 
https://doi.org/10.5194/tc-2021-260

Preprint. Discussion started: 25 August 2021

(c) Author(s) 2021. CC BY 4.0 License.

blowing snow by the total number of hours in that month. Strong seasonal and spatial variability was observed in the monthly cumulative hours with blowing snow occurrence. For example, the total duration of blowing snow events in December and January was up to 255 hours when the threshold of $0.1 \mathrm{~g} \mathrm{~m}^{-2} \mathrm{~s}^{-1}$ was chosen (Figure 5a), accounting for approximately 33.5\% and $34.1 \%$ of these two months (Figure 5d), respectively. However, only 81.7 and 88.4 hours were observed at the Fmon station in the corresponding months, accounting for just $10 \%$ and $11 \%$ of the total hours. At Fmor station, where blowing snow occurred the most frequently of the nine stations, the cumulative blowing snow hours declined from 255 in December and January to 58.83 in September, yielding a $76.99 \%$ decrease. Blwoing snow events at the Fmor station occurred with relatively high or low magnitude accounting $88.4 \%$ of the time (with both magnitudes accounting $44.4 \%$, Figure $5 \mathrm{~d}-\mathrm{f}$ ). Comparative analysis of cumulative hours with different magnitudes of blowing snow reveals that relative high magnitude blowing snow events (where the blowing snow mass flux exceeds $1.0 \mathrm{~g} \mathrm{~m}^{-2} \mathrm{~s}^{-1}$ ) dominated the total blowing snow hours at the majority of stations, accounting for about $50 \%$ of the time, and this proportion was the highest at the Fmor, Fcmb and Fche stations. About $30 \%$ of blowing snow events occurred with a relatively low magnitude, indicating that low intensity blowing snow events occurred much less frequently than high intensity blowing snow events, but more frequently than moderate-intensity blowing snow events. These results further indicate that the French Alps experiences frequent high magnitude blowing snow events.

The blowing snow events in this study are defined by snow transport, where snow mass fluesx exceeding a specific confidence threshold are detected for a minimum duration of $2 \mathrm{~h}$. The mean value for the duration was first determined for each month of the observation period and then averaged to derive the monthly average value. The spatial and seasonal variations in the duration of blowing snow events are presented in Figure 5g-i. As using the lower threshold includes all blowing snow events with transported snow-mass exceeding $0.1 \mathrm{~g} \mathrm{~m}^{-2} \mathrm{~s}^{-1}$, the duration of blowing snow events included in this threshold represents the mean duration of all blowing snow events determined. By analogy, the duration derived at the threshold of $0.5 \mathrm{~g} \mathrm{~m}^{-2} \mathrm{~s}^{-1}$ indicates the mean duration of moderate and high magnitude blowing snow events. seasonal variability was observed in the duration of blowing snow events and shared similar trends with the BSD, the number of occurrences of blowing snow events and the cumulative blowing snow hours. Generally, Fmor, Fhue and Fche were the top three stations with the longest events between January to May (Figure 5g). In particular the Fmor station, where the averaged duration of blowing snow events was roughly 1.5 times longer than the multi-site average in September, October and November. The duration of blowing snow events at the Fmon station in this period was higher than at the other stations, excluding Fmor. However, the patterns show different trends for moderate to high-intensity events ( 0.5 and $1.0 \mathrm{~g} \mathrm{~m}^{-2} \mathrm{~s}^{-1}$ thresholds). A significant decrease in duration was found at the Fmor, Fhue and Fche stations with increasing confidence threshold, except for the Fmon station that experienced a longer duration for high magnitude blowing snow events. For example, the Fche stations experienced a 51.8\% decrease in duration in February (declined from 12.23 to $5.89 \mathrm{~h}$ ), shifting from near-continuous to intermittent occurrence, and the blowing snow events with moderate or high magnitude in November were about 1.18 and 1.37 times longer than the low magnitude blowing snow events. An increase (decrease) of duration with the increase of confidence threshold suggests that high (low) magnitude blowing snow events last longer. Comparative analysis of the number of blowing snow occurrences (Figure 3), cumulative blowing snow hours (Figure 5a-c), and the average duration of each blowing snow event demonstrates 
that a high proportion of blowing snow hours at the Fmor, Fhue and Fche stations were caused by the high frequency of blowing snow occurrences, and relatively long durations in the low magnitude threshold. Although blowing snow events only occurred occasionally in some stations (e.g., Fmon), the long duration of high magnitude blowing snow events sometimes increased the monthly blowing snow hours to be comparable with other stations.

\subsection{Contribution of major blowing snow events}

A major blowing snow event is defined in this study as an event where the blowing snow mass flux exceeds $1.0 \mathrm{~g} \mathrm{~m}^{-2} \mathrm{~s}^{-1}$. Analysis of major blowing snow events allows for a better understanding of the contributions of high magnitude events to the blowing snow-mass transport. The cumulative monthly snow mass flux was calculated and averaged. Figure 6 shows the ratio of the total quantity of mass transported by major blowing snow events compared to all events. A generally high ratio was observed across all stations, although intra-annual variability was especially pronounced at some stations, such as Fhue, Fber, Fgie and Fbon. The Fber station experienced the largest seasonal ratio variations (from 0.67 to 0.97 ), while only 0.1 and 0.06 variations were observed at Fmor and Fmon station, respectively. The significant contribution of major events at the Fmor station can be explained by frequent occurreces with short duration but with a high magnitude of snow transport. The reason was for the constant high ratio at the Fmon station was mostly attributed to the frequent occurrence of high magnitude events.

275 These results demonstrate that although snow-mass transport does not fully depend on the frequency of high magnitude blowing snow occurrences when accompanied by high magnitude snow mass flux and duration of each event, these processes sustain the high ratio of snow transport of major events. From a modeling perspective, an accurate depiction of the occurrence, magnitude and duration of major blowing snow events are crucial for quantitatively investigating the contribution of blowing snow to surface mass balance and subsequent climate impacts.

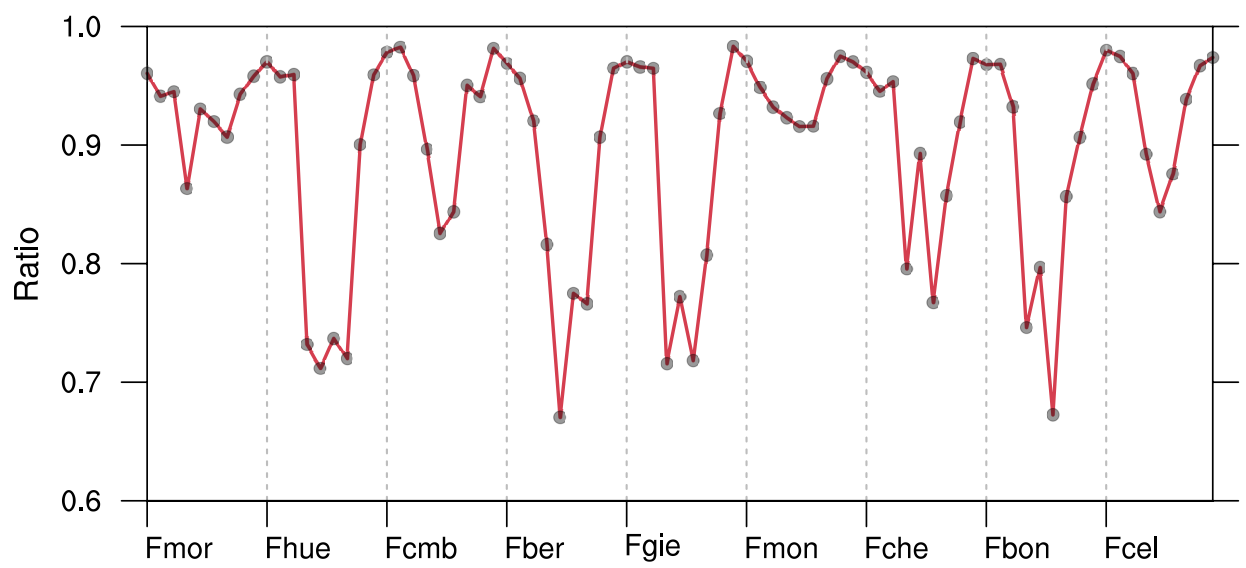

Figure 6. Monthly ratio of snow mass flux transported by major blowing snow events (with blowing snow mass flux exceeding $\left.1.0 \mathrm{~g} \mathrm{~m}^{-2} \mathrm{~s}^{-1}\right)$. 


\subsection{Comparing the frequency of blowing snow occurrences under different meteorological conditions}

The credibility index (CRED) was used to investigate the relative frequency of blowing snow occurrences for a given condition. CRED is defined as the ratio of the number of blowing snow events (p in Eq. 1) that occur under a specific wind speed range, relative to the total number of blowing snow events and non-events ( $\mathrm{n}$ in Eq. 1) within the same range:

$C R E D=\frac{p}{p+n}$
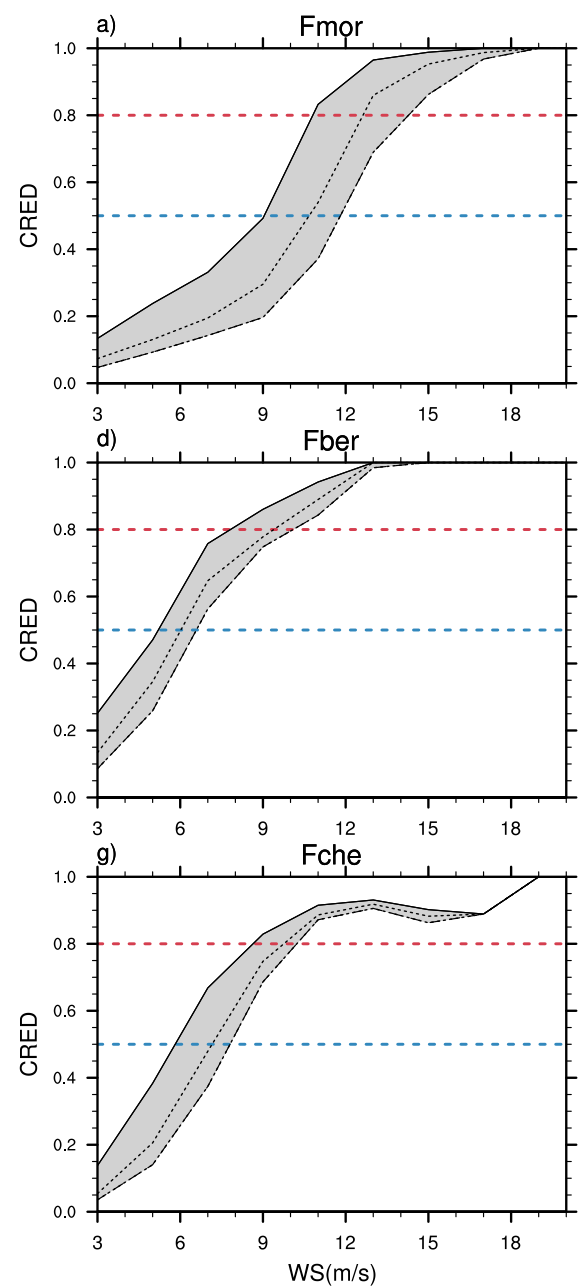
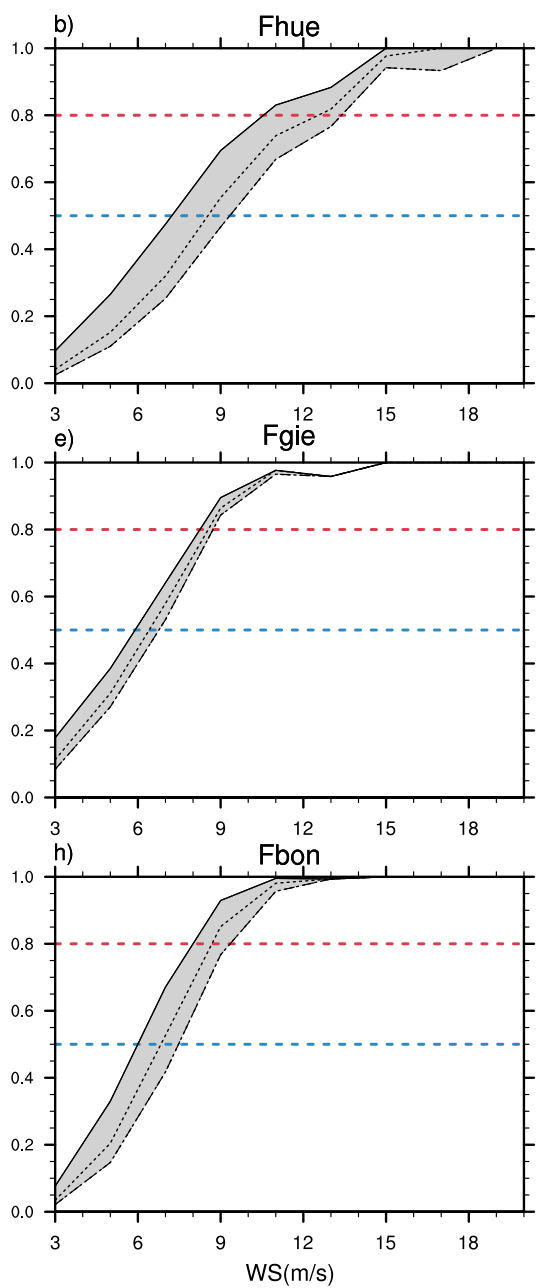
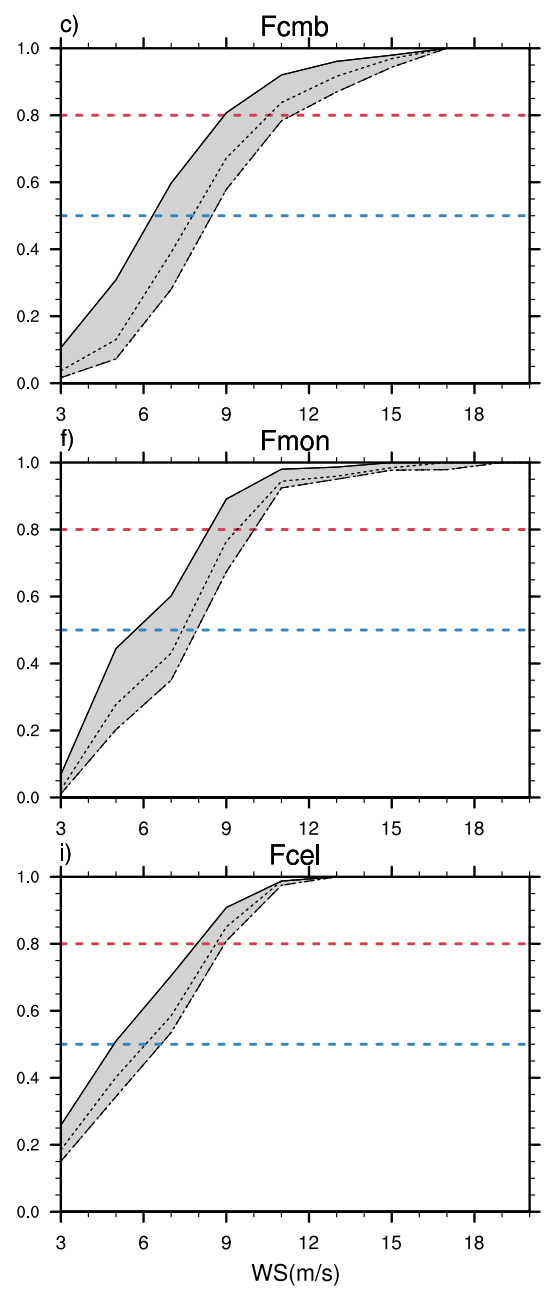

Figure 7. Variability of the credibility index (CRED) with increasing mean wind speed. The shade areas show the range of CRED values calculated at the relaxed and stricter thresholds of 0.1 and $1.0 \mathrm{~g} \mathrm{~m}^{-2} \mathrm{~s}^{-1}$. The CRED values under the threshold of $0.1,0.5$ and 1.0 are represented with the solid line, dotted line and dashed line, respectively. The blue and red dashed lines show the 0.5 and 0.8 CRED values, respectively.

The CRED varies from 0 to 1 , where 0 indicates that no blowing snow event was observed for the given wind condition, and 1 indicates that all wind speeds in that range caused snow transport once the prerequisites (with concurrent snowfall or with snow cover) were met. The CRED was calculated for wind speedsin Figure 7 with a $2 \mathrm{~m} \mathrm{~s}^{-1}$ interval to reduce fluctuation. 
https://doi.org/10.5194/tc-2021-260

Preprint. Discussion started: 25 August 2021

(c) Author(s) 2021. CC BY 4.0 License.

(c) (i)

Maximum wind speeds above $30 \mathrm{~m} \mathrm{~s}^{-1}$ and mean wind speeds above $20 \mathrm{~m} \mathrm{~s}^{-1}$ were not considered as these situations rarely occur.
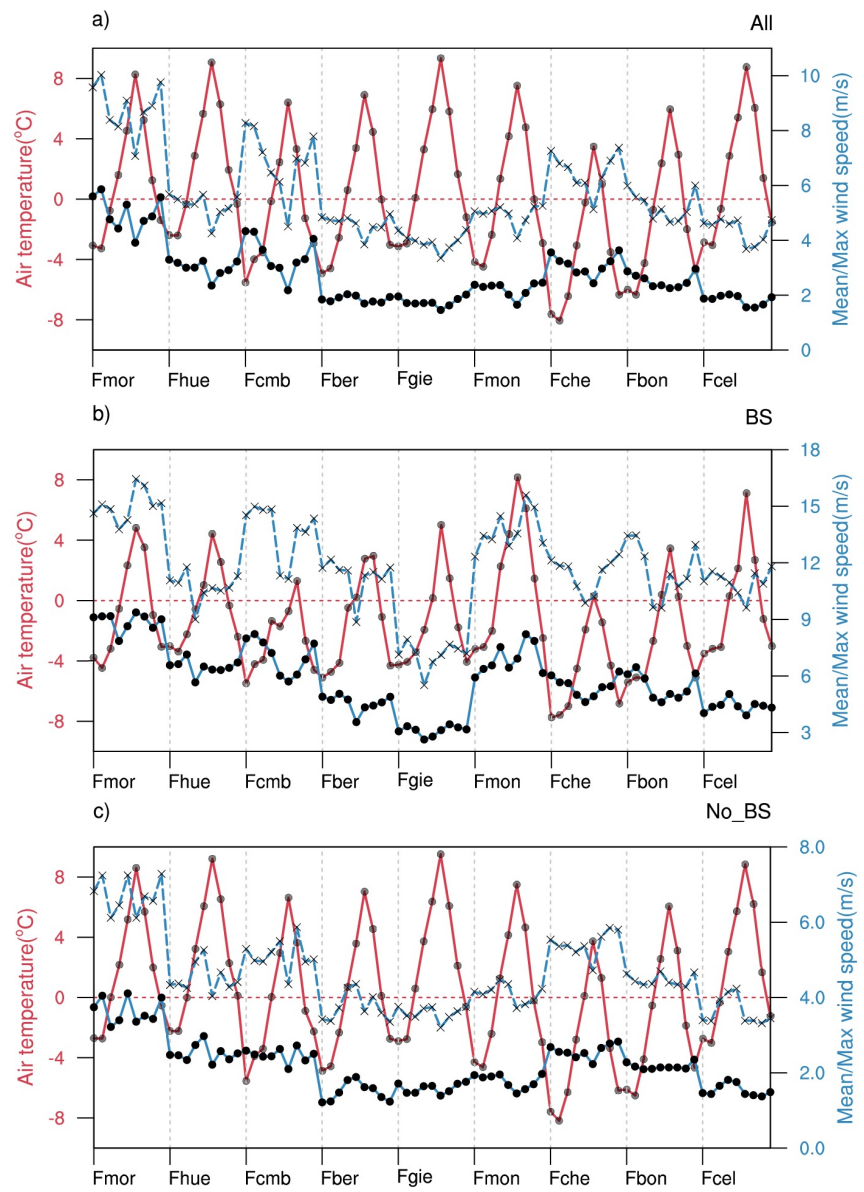

Figure 8. Seasonal variability of (a) mean air temperature (red), mean wind speed (blue line with black dots) and maximum wind speed (blue line with black crosses) of each station during the analysis period with (b) and without (c) blowing snow occurrence.

The CRED distribution (Figure 7) shows an increased probability of blowing snow occurrences with increasing wind speed. Rare blowing snow events with concurrent snowfall and the transport of loose snow within a very short time after deposition were generally responsible for CRED values at relatively low wind speed (below $4.0 \mathrm{~m} \mathrm{~s}^{-1}$ ). The frequency of blowing snow occurrences was sensitive to relatively highwind speeds, with large variations in CRED observed within small intervals. The spatial variability of the wind speed with a $50 \%$ probability of causing blowing snow occurrence ranged from 5.0 to $9.0 \mathrm{~m} \mathrm{~s}^{-1}$ and can be partly explained by differences in local climate (wind speed and air temperature, Figure 8). The occurrence of blowing snow events was restrained by relatively strong inter-particle bonding at Fmor, Fcmb and Fhue stations. The strong bonding resistance at the Fmor and Fcmb stations was attributed primarily to snow compaction from high maximum wind speeds. At Fhue station, the maximum wind speeds were relatively lowand the higher mean wind speed dominated. 
https://doi.org/10.5194/tc-2021-260

Preprint. Discussion started: 25 August 2021

(c) Author(s) 2021. CC BY 4.0 License.

Conversely, the lower snow particle bonding resistance to transport at the Fber and Fcel stations is likely caused by the lower mean and maximum wind speeds facilitating blowing snow occurrences. However, the lower effect of wind on snow compaction at Fgie station was compensated by the strong snow cohesive resistance, which was associated with snow wetness due to high air temperatures. A very high likelihood (CRED $>0.8$ ) of blowing snow was observed at 6 of the 9 stations once the wind speed exceeded $9.0 \mathrm{~m} \mathrm{~s}^{-1}$. Analyzing the CRED distribution provides a simple but efficient way to investigate the

315 likelihood of blowing snow events. Although further research is needed to fully understand blowing snow occurrences, this information provides a valuable foundation for establishing an effective avalanche warning system to reduce risks in ski resorts.
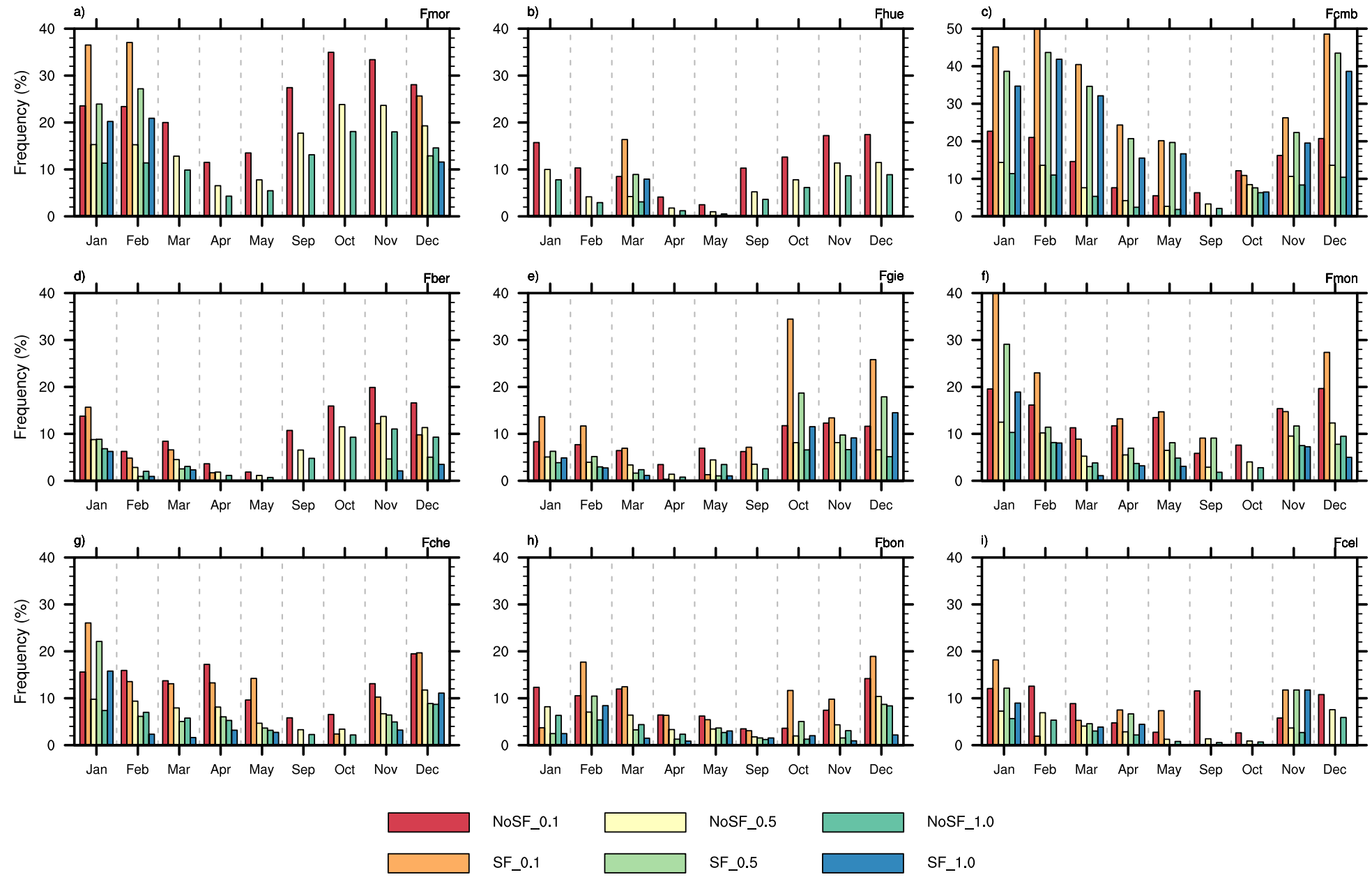

NoSF_1.0

Figure 9. The average monthly probability distribution of blowing snow events with and without concurrent falling snow.

Figure 9 illustrates the average probability distribution of blowing snow events with and without concurrent falling snow

320 at the monthly scale. To prevent misleading results due to small sample sizes, only months that had 10 or more snowfall events were included, meaning that only the probability without concurrent snowfall is shown for some months. For instance, the frequency of blowing snow occurrence with concurrent snowfall at Fhue station for most months is not provided, as snowfall 
https://doi.org/10.5194/tc-2021-260

Preprint. Discussion started: 25 August 2021

(c) Author(s) 2021. CC BY 4.0 License.

was a rare occurrence except in March. Overall, winter months had a higher occurrence of blowing snow events than other seasons (both with and without concurrent falling snow), and events with snowfall often had a higher occurrence than without snowfall. The seasonal contrast was most pronounced at the Fmor, Fcmb and Fmon stations. A generally higher occurrence was observed at Fcmb station than at other sites when snowfall was occurring: typically by up to $50 \%$, while the frequency of blowing snow occurrence at Fmor station was higher than other sites without concurrent falling snow. Strong mean and maximum wind speed contributed to frequent occurrences of blowing snow events at the Fcmb and Fmor stations. However, the underlying mechanisms controlling blowing snow events are likely to be complex as whether blowing snow occurs depends 330 on the various meteorological conditions (particularly wind speed, wind direction and air temperature), complex snow properties (e.g., size, shape and density) and other factors such as topography, vegetation and snow age.
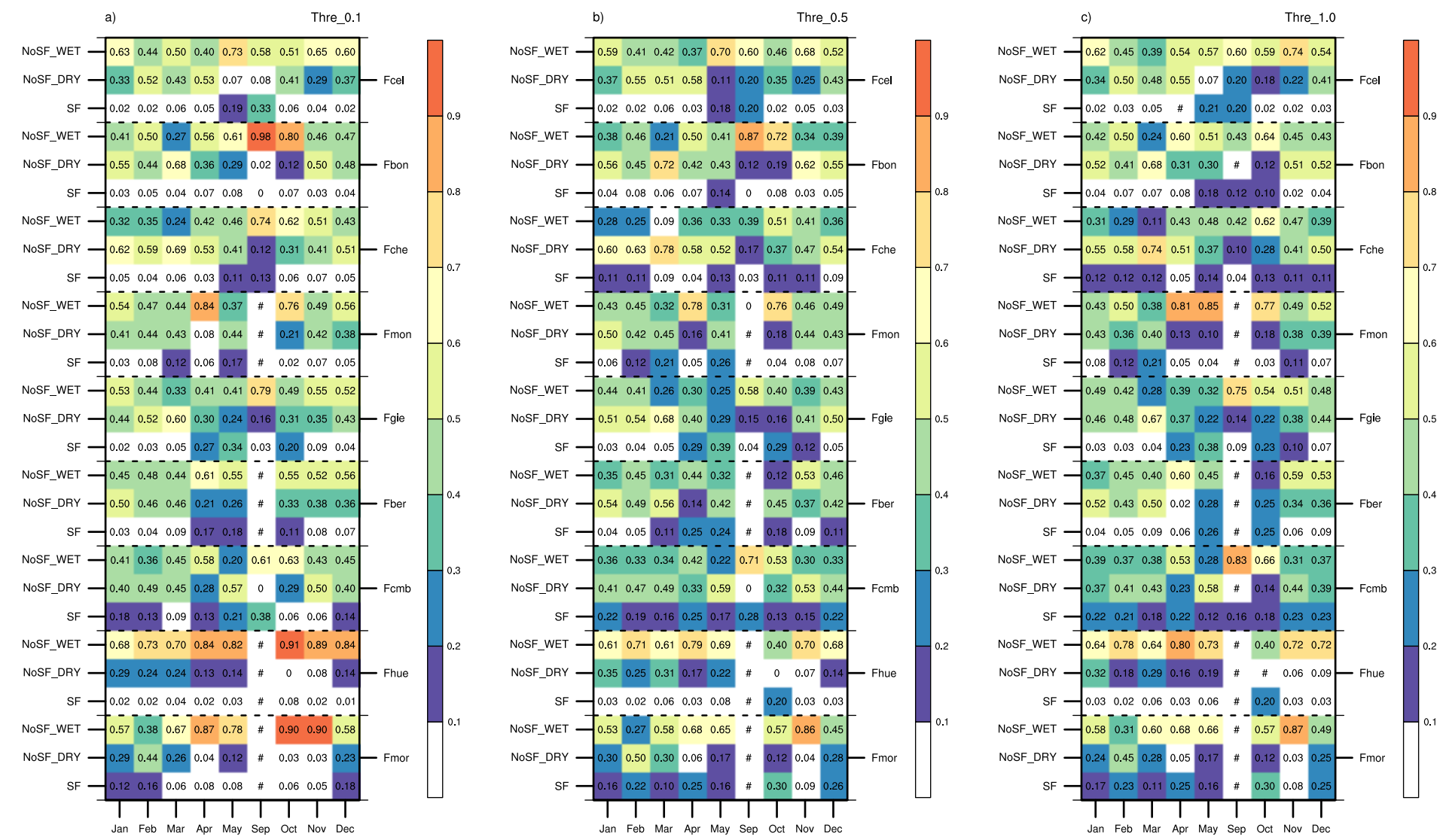

Figure 10. Relative frequency of blowing snow occurrence under SF, NoSF_WET and NoSF_DRY conditions at different confidence thresholds of 0.1 (a), 0.5 (b) and $1.0 \mathrm{~g} \mathrm{~m}^{-2} \mathrm{~s}^{-1}$ (c). The pound sign (\#) indicates that the relative frequency is unaviliable because snowfall events rare occur for some months.

The relative frequency of blowing snow occurrence under the different conditions was analyzed to further investigate the impacts of ambient meteorological conditions on blowing snow events. The monthly relative frequency of the three categories (Figure 10) was obtained by dividing the respective number of blowing snow events by the total number of events 
in that month. The stations were dominated by wet snow transport in the spring and autumn, linked to snowfall, snowmelt and fluctuating changes of air temperature near the freezing point during these seasons. The occurrence of blowing snow at the Fmor, Fhue and Fmon stations was dominated by wet snow transport throughout the year. This finding was especially pronounced for the Fhue and Fmor stations, where the proportion of blowing snow events occurring under wet snow conditions was as high as $90 \%$ in autumn. A plausible reason for this trend was the rapid phase transition of snow particles due to the frequent temperature fluctuations in autumn. The frequency of blowing snow with concurrent snowfall was significantly lower than with either dry or wet snow conditions throughout the year. This result is because snowfall is a relatively infrequent weather event, particularly at the Fhue and Fbon stations, where the relative frequency of blowing snow events with snow mass fluxes exceeding $0.1 \mathrm{~g} \mathrm{~m}^{-2} \mathrm{~s}^{-1}$ accounted for less than $10 \%$ of blowing snow occurrences throughout the year. The frequency with concurrent snowfall at the Fcmb station was higher than at other stations, with the highest value was observed in September (38\%). However, the number of blowing snow events occurring in that month did not exceed 10 (Figure 2c), suggesting that this high relative frequency was mainly caused by the very low frequency of blowing snow occurrences (only 5 times on average, Figure 3c). In May, the frequency of occurrences accompanying falling snow at Fgie station was high at $34 \%$, while the probability of blowing snow occurrence with concurrent snowfall in that month was only 1.3\% (Figure 9e), indicating the snowfall frequently occurred and made a significant contribution to the occurrence of snow transport in that month.

Comparative analysis of the relative frequency of blowing snow events with varying thresholds shows that the proportion of wet snow transport decreased significantly (the vast majority of frequencies were below 50\%) with increasing intensity snow mass flux from light to moderate magnitude 0.1 to $0.5 \mathrm{~g} \mathrm{~m}^{-2} \mathrm{~s}^{-1}$ ), while the proportion of occurrences under dry snow conditions or with concurrent snowfall increased. The proportion remained relatively unchanged at Fhue, Fbon and Fcel stations when concurrent snowfall was observed. The reason for this trend at the Fhue station was because of the occasional occurrence of snowfall, while the latter two stations were due to extremely low proportion of blowing snow with concurrent snowfall. A decrease was observed in the percentage of dry snow transport when the magnitude of blowing snow events increased from 0.5 to $1.0 \mathrm{~g} \mathrm{~m}^{-2} \mathrm{~s}^{-1}$, while changes in the proportion under snowfall or wet snow conditions were negligible. These results indicate that blowing snow occurrences with concurrent snowfall were generally more intense but that the number of blowing snow occurrences did not vary significantly with the increasing thresholds. Instead, changes in the threshold correspond to significant variation in the proportion of blowing snow events occurring under either dry or wet snow conditions, as the transported wet snow and dry snow mass flux were mostly concentrated in the range of 0.1 to $0.5 \mathrm{~g} \mathrm{~m}^{-2} \mathrm{~s}^{-1}$ and 0.5 to 1.0 $\mathrm{g} \mathrm{m}^{-2} \mathrm{~s}^{-1}$, respectively.

The distribution of observed wind direction at each site and the corresponding frequency of blowing snow occurrence with different thresholds are shown in Figure 11. The probability of blowing snow occurrence with a particular wind direction was calculated based on the ratio of the number of blowing snow events to the total records of periods with the corresponding wind direction. Analyses for different snow conditions in different seasons were conducted but only the general distribution under different snow conditions are discussed here. As shown in Figure 11, the observed prevailing wind direction varied 
https://doi.org/10.5194/tc-2021-260

Preprint. Discussion started: 25 August 2021

(c) Author(s) 2021. CC BY 4.0 License.

(c) (i)

significantly between stations, with contrasting patterns for the probability of occurrence in different directions. The prevailing wind direction is closely related to large-scale atmospheric circulation and local topography, while the occurrence probability of blowing snow under each direction is also influenced by the ambient meteorological conditions and snowpack properties.

375 The following four scenarios explain the relationship between prevailing wind direction and the probability of blowing snow occurrence.
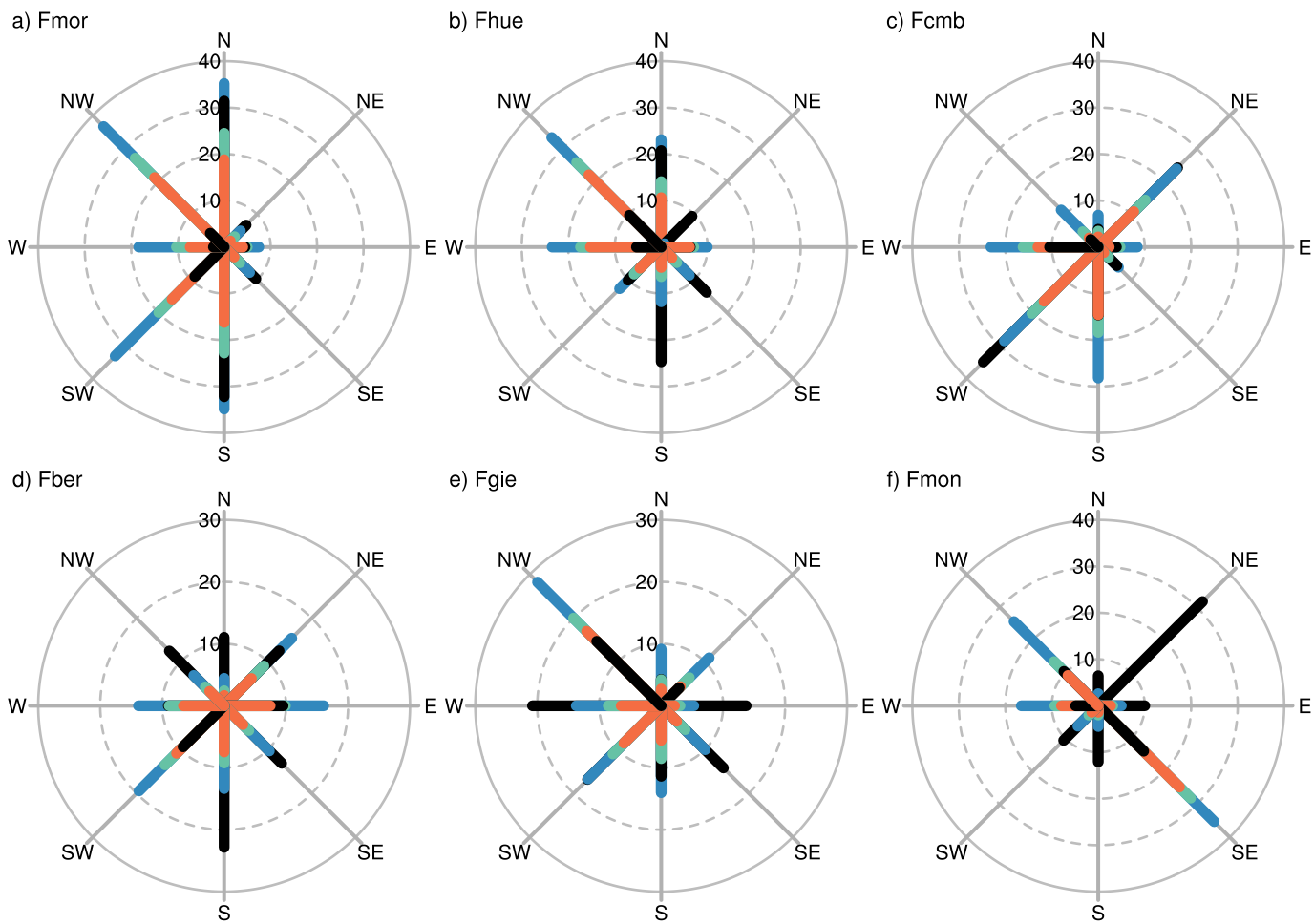

e) Fgie

f) Fmon
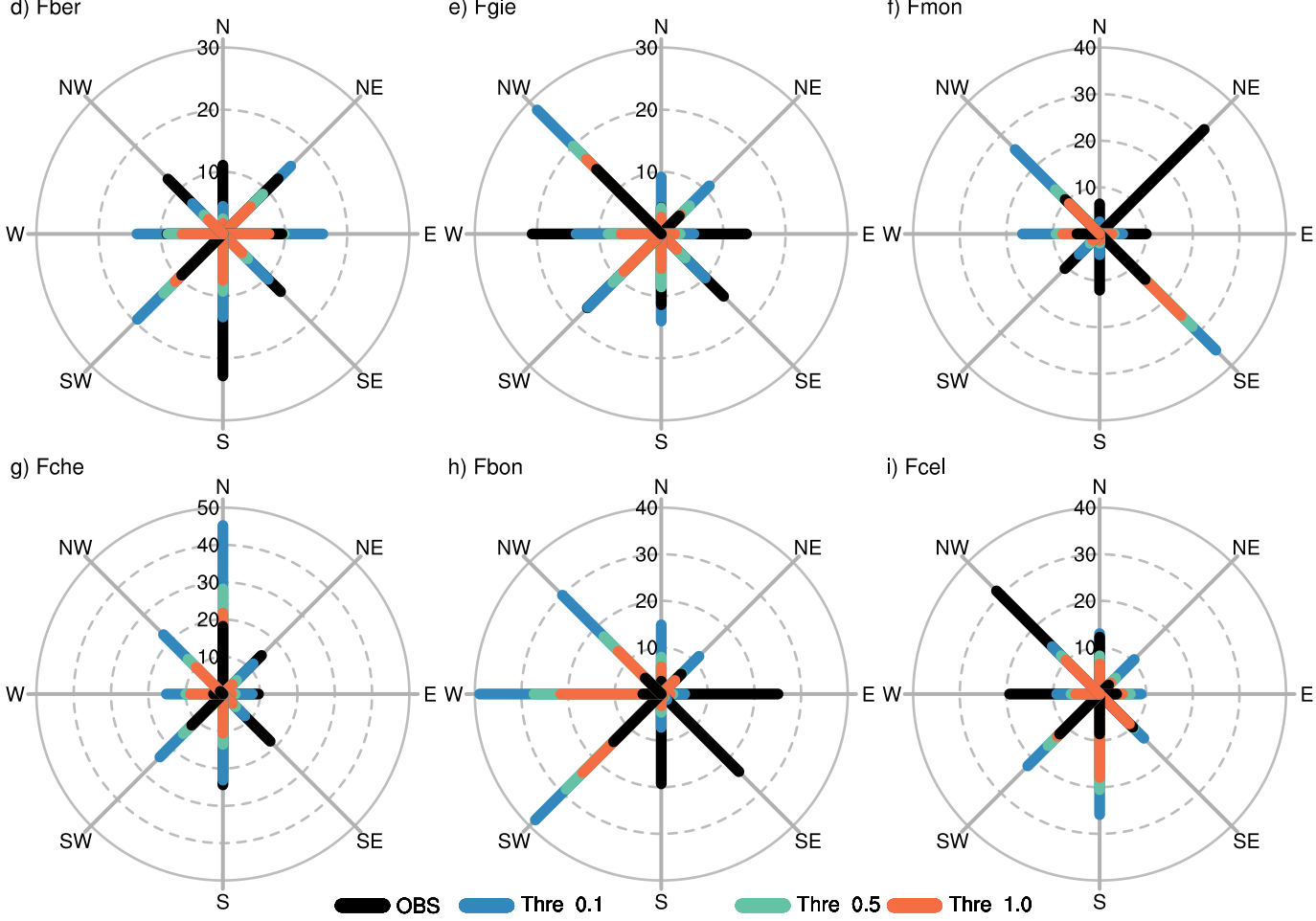

h) Fbon

i) Fcel

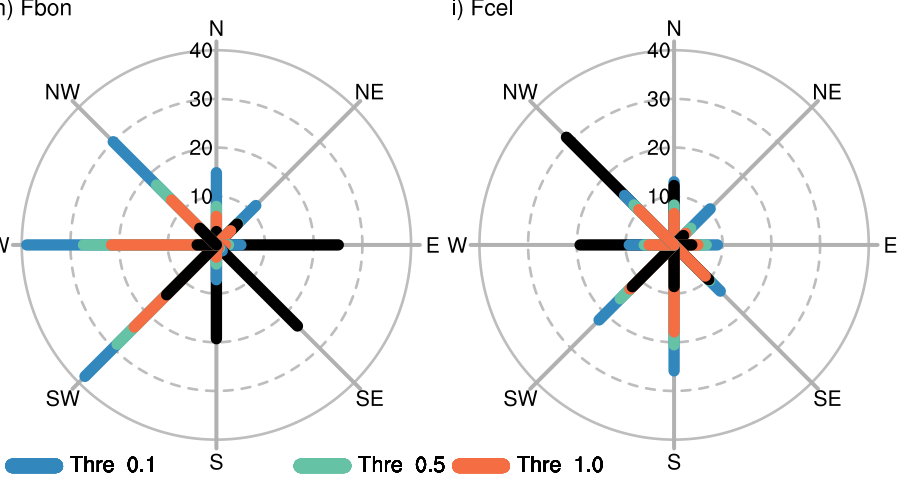

Figure 11. Distribution of observed wind direction at each site and the corresponding frequency characteristics of blowing snow occurrence under different thresholds. The observed prevailing wind direction is shown by the black bar, while the blue, green and orange bars denote the relative frequency of blowing snow occurrence at the corresponding direction at the thresholds of $0.1,0.5$ and $1.0 \mathrm{~g} \mathrm{~m}^{-2} \mathrm{~s}^{-1}$, respectively. 
1. The wind comes from a prevailing direction, and the corresponding occurrence probability is high, suggesting that blowing snow frequently occurs in that direction. Examples of this scenario are with northly and southeasterly winds at Fcmb station.

2. The wind comes from a prevailing direction, but the corresponding occurrence probability is low, so the occurrence of blowing snow mainly depends on the frequency of that wind occurs in this direction, such as with a northwesterly direction at Fmor station.

3. The wind comes from an infrequent direction but has a high probability of blowing snow occurrence, meaning that once wind occurs in that direction, it is most likely to be accompanied by blowing snow. However, blowing snow events occur less frequently in that direction compared to other directions, as is the case for westerly direction at Fbon station.

4. The wind comes from an infrequent direction that is associated with a low probability of blowing snow occurrence, meaning that blowing snow events rarely occur in that direction. An example of this is with northwesterly and easterly wind directions at Fmor station.

Due to the significant instability and randomness of wind direction in this region, coupled with the complex influence of local topography and atmospheric circulation, we conclude that wind direction is not an effective factor to estimate the occurrence of blowing snow. This finding corroborates previous research that excluded wind direction as a feature variable in constructing a decision tree model for blowing snow detection based on conventional meteorological measurements (Xie et al., 2021).

\section{Summary}

Near-surface measurements of blowing snow provide valuable information that cannot be determined remotely or visually, facilitating the development of numerical models and satellite retrieval algorithms. Meteorological observations and snow mass flux from nine stations were analyzed to investigate the spatiotemporal variability of blowing snow events in the French Alps. This study shows that there are frequent blowing snow events, which display contrasting patterns of seasonal variability is observed in this region. The average number of blowing snow days across all the stations ranges from 5.0 to 14.3 days using

405 a snow flux threshold of $0.1 \mathrm{~g} \mathrm{~m}^{-2} \mathrm{~s}^{-1}$, accounting for between $16.7 \%$ and $46.1 \%$ of the time. The maximum and minimum frequency of blowing snow days are in January and September, respectively. At Fmor and Fcmb stations, blowing snow events occur for as many as two out of three days in January, and the seasonal variability is more pronounced at these two stations. The frequency of monthly blowing snow days varies widely between the stations, and this trend is more pronounced for the lower snow mass flux threshold. The significant spatial variability is not dependent on the elevation and is related to local ambient conditions, such as mean and maximum wind speed. Comparisons of the number of blowing snow days derived from various thresholds of snow mass flux indicate that blowing snow events with high magnitude snow mass flux $\left(1.0 \mathrm{~g} \mathrm{~m}^{-2} \mathrm{~s}^{-1}\right)$ occur more frequently than low-intensity events $\left(0.1\right.$ to $\left.0.5 \mathrm{~g} \mathrm{~m}^{-2} \mathrm{~s}^{-1}\right)$. Using a minimum duration of $2 \mathrm{~h}$ to define a blowing snow events, the monthly cumulative hours with blowing snow at Fmor station in December and January is 255 hours under 
https://doi.org/10.5194/tc-2021-260

Preprint. Discussion started: 25 August 2021

(c) Author(s) 2021. CC BY 4.0 License.

(c) (i)

the threshold of $0.1 \mathrm{~g} \mathrm{~m}^{-2} \mathrm{~s}^{-1}$, accounting for roughly $34 \%$ of the month. However, significant seasonal and spatial variability 415 are present across the region. The observations also demonstrate that the contribution of snow mass transported during relative high magnitude blowing snow events (with blowing snow mass flux exceeds $1.0 \mathrm{~g} \mathrm{~m}^{-2} \mathrm{~s}^{-1}$ ) accounts for about $90 \%$ of the transported snow mass. The cumulative hours of major events account for less than $50 \%$ of blowing snow events, highlighting the importance to accurately represent of major blowing snow event sin terms of occurrence, magnitude and duration to investigate the contribution of blowing snow on the surface mass balance and the climate. A very high likelihood (CRED $>0.8)$ of blowing snow is observed when the mean wind speed exceeds $9.0 \mathrm{~m} \mathrm{~s}^{-1}$, and the considerable variability between stations stems from differences in localized climate (e.g., wind speed and air temperature). Blowing snow events with concurrent snowfall are generally associated with intense snow transport (with a snow mass flux above $1.0 \mathrm{~g} \mathrm{~m}^{-2} \mathrm{~s}^{-1}$ ). Transport of wet snow and dry snow are mostly concentrated in the range of 0.1 to $0.5 \mathrm{~g} \mathrm{~m}^{-2} \mathrm{~s}^{-1}$ and 0.5 to $1.0 \mathrm{~g} \mathrm{~m}^{-2} \mathrm{~s}^{-1}$, respectively.

Overall, the in-situ blowing snow observations presented in this study provide valuable information to improve our 425 understanding of the spatiotemporal variability of blowing snow occurrences and the potential links between the occurrence and magnitude of blowing snow events with ambient meteorological conditions. Although the site-scale observations only represent local conditions, these data allow for continuous and autonomous detection of blowing snow occurrences under different conditions and enable quantitative evaluations of satellite retrieval algorithms and blowing snow models.

430 Data availability. Observation from the ISAW stations including the routine meteorological data and FlowCapt snow mass flux data can be accessed at http:www.iav.ch.

Author contribution. ZPX was responsible for the conceptualization and data processing. ZPX performed the formal analysis and prepared the manuscript with contributions from all co-authors. YMM, WQM, ZYH and GHS modified the manuscript.

Competing interests. The authors declare that they have no conflict of interests.

Acknowledgments. This work was supported by the National Natural Science Foundation of China (41905012), the Second Tibetan Plateau Scientific Expedition and Research (STEP) program (2019QZKK0103), and the China Postdoctoral Science 440 Foundation (2018M641489). We would like to express our special appreciation and thanks to the scientists and engineers who involved in maintain the normal operations of the measurements from ISAW stations. 
https://doi.org/10.5194/tc-2021-260

Preprint. Discussion started: 25 August 2021

(c) Author(s) 2021. CC BY 4.0 License.

(c) (i)

\section{References}

Agosta, C., Amory, C., Kittel, C., Orsi, A., Favier, V., Gallee, H., van den Broeke, M. R., Lenaerts, J. T. M., van Wessem, J. M., van de Berg, W. J., and Fettweis, X.: Estimation of the Antarctic surface mass balance using the regional climate model MAR (1979-2015) and identification of dominant processes, Cryosphere, 13, 281-296, 10.5194/tc-13-281-2019, 2019.

Amory, C.: Drifting-snow statistics from multiple-year autonomous measurements in Adelie Land, East Antarctica, Cryosphere, 14, 1713-1725, 10.5194/tc-14-1713-2020, 2020.

Barnett, T. P., Adam, J. C., and Lettenmaier, D. P.: Potential impacts of a warming climate on water availability in snowdominated regions, Nature, 438, 303-309, 10.1038/nature04141, 2005.

Barral, H., Genthon, C., Trouvilliez, A., Brun, C., and Amory, C.: Blowing snow in coastal Adelie Land, Antarctica: three atmospheric-moisture issues, Cryosphere, 8, 1905-1919, 10.5194/tc-8-1905-2014, 2014.

Berghuijs, W. R., Woods, R. A., and Hrachowitz, M.: A precipitation shift from snow towards rain leads to a decrease in streamflow, Nature Climate Change, 4, 583-586, 10.1038/nclimate2246, 2014.

Chen, X., Long, D., Hong, Y., Liang, S., and Hou, A.: Observed radiative cooling over the Tibetan Plateau for the past three decades driven by snow cover-induced surface albedo anomaly, Journal of Geophysical Research-Atmospheres, 122, 6170-6185, 10.1002/2017jd026652, 2017.

Chritin, V., Bolognesi, R., and Gubler, H.: FlowCapt: a new acoustic sensor to measure snowdrift and wind velocity for avalanche forecasting, Cold Regions Science and Technology, 30, 125-133, 10.1016/s0165-232x(99)00012-9, 1999.

Cline, D. W.: Snow surface energy exchanges and snowmelt at a continental, midlatitude Alpine site, Water Resources Research, 33, 689-701, 10.1029/97wr00026, 1997.

Dery, S. J. and Yau, M. K.: A bulk blowing snow model, Boundary-Layer Meteorology, 93, 237-251, 10.1023/a:1002065615856, 1999.

Dery, S. J. and Yau, M. K.: Large-scale mass balance effects of blowing snow and surface sublimation, Journal of Geophysical Research-Atmospheres, 107, 10.1029/2001jd001251, 2002.

Goodrich, L. E.: THE INFLUENCE OF SNOW COVER ON THE GROUND THERMAL REGIME, Canadian Geotechnical Journal, 19, 421-432, 10.1139/t82-047, 1982.

Gossart, A., Souverijns, N., Gorodetskaya, I. V., Lhermitte, S., Lenaerts, J. T. M., Schween, J. H., Mangold, A., Laffineur, Q., and van Lipzig, N. P. M.: Blowing snow detection from ground-based ceilometers: application to East Antarctica, Cryosphere, 11, 2755-2772, 10.5194/tc-11-2755-2017, 2017.

Guyomarc'h, G. and Merindol, L.: Validation of an application for forecasting blowing snow, in: Annals of Glaciology, Vol 26, 1998, edited by: McClung, D. M., Annals of Glaciology, 138-143, 10.3189/1998AoG26-1-138-143, 1998. 
https://doi.org/10.5194/tc-2021-260

Preprint. Discussion started: 25 August 2021

(c) Author(s) 2021. CC BY 4.0 License.

(c) (i)

Guyomarc'h, G., Bellot, H., Vionnet, V., Naaim-Bouvet, F., Deliot, Y., Fontaine, F., Pugliese, P., Nishimura, K., Durand, Y., and Naaim, M.: A meteorological and blowing snow data set (2000-2016) from a high-elevation alpine site (Col du Lac Blanc, France, 2720 m a.s.1.), Earth System Science Data, 11, 57-69, 10.5194/essd-11-57-2019, 2019.

He, S. and Ohara, N.: A New Formula for Estimating the Threshold Wind Speed for Snow Movement, Journal of Advances in Modeling Earth Systems, 9, 2514-2525, 10.1002/2017ms000982, 2017.

Huang, Q., Hanesiak, J., Savelyev, S., Papakyriakou, T., and Taylor, P. A.: Visibility during blowing snow events over Arctic sea ice, Weather and Forecasting, 23, 741-751, 10.1175/2008waf2007015.1, 2008.

Lenaerts, J. T. M., van den Broeke, M. R., Dery, S. J., van Meijgaard, E., van de Berg, W. J., Palm, S. P., and Rodrigo, J. S.: Modeling drifting snow in Antarctica with a regional climate model: 1. Methods and model evaluation, Journal of Geophysical Research-Atmospheres, 117, 10.1029/2011jd016145, 2012.

Leonard, K. C., Tremblay, L. B., Thom, J. E., and MacAyeal, D. R.: Drifting snow threshold measurements near McMurdo station, Antarctica: A sensor comparison study, Cold Regions Science and Technology, 70, 71-80, 10.1016/j.coldregions.2011.08.001, 2012.

Letcher, T. W., LeGrand, S. L., and Polashenski, C.: Applying a Physically Based Blowing Snow Diagnostic Parameterization to Improve Wintertime Visibility Forecasts in the WRF Model, Weather and Forecasting, 36, 615-626, 10.1175/wafd-20-0106.1, 2021.

Li, L. and Pomeroy, J. W.: Estimates of threshold wind speeds for snow transport using meteorological data, Journal of Applied Meteorology, 36, 205-213, 10.1175/1520-0450(1997)036<0205:Eotwsf>2.0.Co;2, 1997.

Liston, G. E. and Sturm, M.: A snow-transport model for complex terrain, Journal of Glaciology, 44, 498-516, 10.3189/s0022143000002021, 1998.

Liston, G. E., Haehnel, R. B., Sturm, M., Hiemstra, C. A., Berezovskaya, S., and Tabler, R. D.: Instruments and methods simulating complex snow distributions in windy environments using SnowTran-3D, Journal of Glaciology, 53, 241256, 10.3189/172756507782202865, 2007.

Mann, G. W., Anderson, P. S., and Mobbs, S. D.: Profile measurements of blowing snow at Halley, Antarctica, Journal of Geophysical Research-Atmospheres, 105, 24491-24508, 10.1029/2000jd900247, 2000.

Mellor, M.: Gauging Antarctic drift snow, Antarctic Meteorology, 347-354, 1960.

500 Musselman, K. N., Addor, N., Vano, J. A., and Molotch, N. P.: Winter melt trends portend widespread declines in snow water resources, Nature Climate Change, 11, 418-+, 10.1038/s41558-021-01014-9, 2021.

Naaim-Bouvet, F., Bellot, H., Nishimura, K., Genthon, C., Palerme, C., Guyomarc'h, G., and Vionnet, V.: Detection of snowfall occurrence during blowing snow events using photoelectric sensors, Cold Regions Science and Technology, 106, 11-21, 10.1016/j.coldregions.2014.05.005, 2014.

505 Palm, S. P., Kayetha, V., and Yang, Y.: Toward a Satellite-Derived Climatology of Blowing Snow Over Antarctica, Journal of Geophysical Research-Atmospheres, 123, 10282-10294, 10.1029/2018jd028632, 2018. 
https://doi.org/10.5194/tc-2021-260

Preprint. Discussion started: 25 August 2021

(c) Author(s) 2021. CC BY 4.0 License.

\section{(c) (1)}

Palm, S. P., Yang, Y., Spinhirne, J. D., and Marshak, A.: Satellite remote sensing of blowing snow properties over Antarctica, Journal of Geophysical Research-Atmospheres, 116, 10.1029/2011jd015828, 2011.

Pomeroy, J. W., Gray, D. M., and Landine, P. G.: THE PRAIRIE BLOWING SNOW MODEL - CHARACTERISTICS, VALIDATION, OPERATION, Journal of Hydrology, 144, 165-192, 10.1016/0022-1694(93)90171-5, 1993.

Sato, T., Kimura, T., Ishimaru, T., Maruyama, T., and Int Glaciol Soc; Int Glaciol Soc; Int Glaciol, S. O. C.: FIELD-TEST OF A NEW SNOW-PARTICLE COUNTER (SPC) SYSTEM, in: Annals of Glaciology, Vol 18, 1993: Proceedings of the Symposium on Snow and Snow-Related Problems, Annals of Glaciology-Series, 149-154, 10.1017/s0260305500011411, 1993.

Schmidt, R. A.: THRESHOLD WIND-SPEEDS AND ELASTIC IMPACT IN SNOW TRANSPORT, Journal of Glaciology, 26, 453-467, 10.3189/s0022143000010972, 1980.

Schmidt, R. A.: ESTIMATES OF THRESHOLD WINDSPEED FROM PARTICLE SIZES IN BLOWING SNOW, Cold Regions Science and Technology, 4, 187-193, 10.1016/0165-232x(81)90003-3, 1981.

Trouvilliez, A., Naaim-Bouvet, F., Genthon, C., Piard, L., Favier, V., Bellot, H., Agosta, C., Palerme, C., Amory, C., and Gallee, H.: A novel experimental study of aeolian snow transport in Adelie Land (Antarctica), Cold Regions Science and Technology, 108, 125-138, 10.1016/j.coldregions.2014.09.005, 2014.

van Wessem, J. M., van de Berg, W. J., Noel, B. P. Y., van Meijgaard, E., Amory, C., Birnbaum, G., Jakobs, C. L., Krueger, K., Lenaerts, J. T. M., Lhermitte, S., Ligtenberg, S. R. M., Medley, B., Reijmer, C. H., van Tricht, K., Trusel, L. D., van Ulft, L. H., Wouters, B., Wuite, J., and van den Broeke, M. R.: Modelling the climate and surface mass balance of polar ice sheets using RACMO2-Part 2: Antarctica (1979-2016), Cryosphere, 12, 1479-1498, 10.5194/tc-12-14792018, 2018.

Vionnet, V., Guyomarc'h, G., Lafaysse, M., Naaim-Bouvet, F., Giraud, G., and Deliot, Y.: Operational implementation and evaluation of a blowing snow scheme for avalanche hazard forecasting, Cold Regions Science and Technology, 147, 1-10, 10.1016/j.coldregions.2017.12.006, 2018.

530 Xiao, M.: A warning of earlier snowmelt, Nature Climate Change, 11, 380-381, 10.1038/s41558-021-01024-7, 2021.

Xie, Z., Hu, Z., Ma, Y., Sun, G., Gu, L., Liu, S., Wang, Y., Zheng, H., and Ma, W.: Modeling Blowing Snow Over the Tibetan Plateau With the Community Land Model: Method and Preliminary Evaluation, Journal of Geophysical ResearchAtmospheres, 124, 9332-9355, 10.1029/2019jd030684, 2019.

Zhang, T. J.: Influence of the seasonal snow cover on the ground thermal regime: An overview, Reviews of Geophysics, 43, $10.1029 / 2004 \operatorname{rg} 000157,2005$. 